\title{
The Effects of the Extended Triad Model and Cognitive Style on the Abilities of Mathematical Representation and Proving of Theorem
}

\author{
$1^{\text {st }}$ Wahyu Widada \\ Mathematics Education Program, \\ Universitas Bengkulu \\ Bengkulu, Indonesia \\ Corresponding author: \\ wahyu.unib@gmail.com
}

\author{
$2^{\text {nd }}$ Dewi Herawaty \\ Mathematics Education Program, \\ Universitas Bengkulu \\ Bengkulu, Indonesia \\ dewiherawaty71@gmail.com
}

\begin{abstract}
This research seeks to address the effect of extended triad learning model on the abilities of mathematical representation and to prove theorem when controlled by cognitive style covariate. This research applied the quasi-experimental method with a $2 \times 2$ factorial design. Data were analyzed by covariate analysis. The result of this research was: 1) The influence of extended triad model to student's mathematical representation of the real analysis more better than the conventional learning model when controlled by cognitive style covariate; 2) The influence of extended triad learning model on the students' proofing theorem ability of the real analysis more better than the conventional learning model when controlled by cognitive style covariate.
\end{abstract}

Keywords-Ability Mathematical Representation, Proof Theorem, Extended Triad

\section{INTRODUCTION}

Several studies highlight that majority of students' real-time analytical skills are still at a low level [1-4]. Research data conducted by Widada \& Herawaty shows about $49.5 \%$ of students were the bottom level [1]. The level that they were capable of is in separating actions or objects, but they cannot establish relationships of actions, processes or objects, and the rest of them can only perform actions and actions separately and unable to reach processes or objects [23, 5-14]. The students were an intra level [15]. According to the personal experience as a lecturer of real analysis, the low level of cognitive level of students in understanding the concepts and principles of real analysis is caused by the difficulties of students in the process of mathematical representation and the weakness of the students' ability in the process of proving the theorem. Also found students made mistakes such as misinterpreting phrases, field axioms or order of operations and others [16]. Although the actual proofs of principles in mathematics have been introduced since high school at different levels [17], there are still many student errors in the proofing process. Therefore, learning improvisation is needed. Knuth states that one method for teaching proofs calls for the clarification of the difference between proofs that explain and proofs that merely prove [18]. The cognitive structure-based learning model conflicts with the weaknesses of students' cognitive processes [12].

Cognitive theories viewed the individual as an active information processor, so that the individual is able to represent each information according to the level of knowledge possessed, and create it as a representative structure of knowledge in the form of frames or in the form of schemes, or in the form of scripts stored in memory [19-22]. The structure of the representation of mathematical knowledge can be seen in the mental construction of a person who is made to achieve and understand the concepts and principles of mathematics. An understanding of mathematical concepts is the result of the construction or reconstruction of mathematical objects. Construction or reconstruction was done through activities in the form of math actions, processes, objects organized in a scheme to solve a problem. It can be analyzed through a genetic decomposition analysis as an operationalization of APOS theory [8].

Regarding the literatures which states a mature scheme of a mathematical fragment is a coherent system of actions, processes, objects, and other schemes that have been previously built, coordinated and synthesized by individuals in the form of structures used to deal with a particular problem 
situation [5-10]. Certain mathematical passages in this regard have broader meanings of mathematical objects (such as facts, concepts, principles, and rules) but include the conception of mathematical objects, as well as other fragments related to problem-solving.

Therefore, to teach students to reach a high level of proof of the theorem and mathematical representation requires a learning model that matches the character of the student. The learning model is the extended triad model [3,14]. De Villiers [23] states that the role of experimentation in learning about mathematical proofing is an application of the conceptual framework in developing mathematics education curriculum and as a basis for evaluating learning activities and curriculum. The application of the learning model above will have a positive impact on the increase in student abstraction ability level. According to Widada there were six levels of abstraction performed by students in understanding mathematical objects, namely Level 0 (Concrete Objects), Level (Semiconcrete Models), Level 2 (Theoretical Models), Level 3 (Languages in Sample Domains), Level 4 (Math Language), and Level 5 (Inference Model) [4,24].

The increasing of the abstraction level it leads to a positive understanding of mathematical concepts and principles [24]. Along with the improvement of understanding of concepts and principles, the ability to perform the process of a proof theorem and mathematical representation will also increase. The improvement of an improvement in the network of students' knowledge representation structures as stated in the extended triad levels $[1,3,4,14]$. According to Widada, the syntax of the extended triad learning model include (1) Problem-Giving Phases in accordance with the Student Scheme, (2) Thinking Phase, (3) Phase Pair, (4) Exploration Phase, (5) Exploration Discussion Phase, (6) Conclusion Phase [25]. In the learning process that involves student cognition actively, the cognitive style becomes the accompanying variable. Pretz, JE et al. found that individual differences in both cognitive ability and cognitive style were associated with variability in implicit learning scores [26]. According to Witkin, et al. cognitive styles can be distinguished, i.e., independent field and field dependent [27]. Cognitive style field dependence/independence is the only variable influencing the achievement in mathematics and Slovene language in co-operative learning. The highest were gains in field-dependent students, then gains in field-independent students [28]. Based on [29], the students' results of mathematical problemsolving learning acquired who had cognitive style field independent (FI) was more excellent than the students who had the cognitive style of field dependent (FD).
There was an interaction effect toward the learning strategy by using the cognitive style on mathematical problem-solving learning outcomes. Ratumanan found that the result of learning the mathematics field independent students better when compared with the field dependent one [30]. Properly structured cooperative learning can be beneficial to all students, regardless of their level of ability, gender or cognitive style [28].

Based on the description above, this paper discussed the "Influence of Extended Triad Learning Model and Cognitive Style on Mathematical Representation Ability and Proving Theorem."

\section{METHODS}

This research applied the quasi-experimental method with a $2 \times 2$ factorial design. This design aims to examine the similarity between groups, and cognitive style as a covariate as a statistical control.

The population of this research was all students of mathematics education of Bengkulu University and Muhammadiyah University of Bengkulu academic year 2016/2017. The sample of this research were 126 students selected with an intact group. There are two dependent variables: the ability to prove theorems and the ability of mathematical representation. The cognitive style acts as a covariate, and the learning model as the independent variable. The extended triad learning model was applied to the experimental class and the conventional learning model for the control class.

The instrument of this study there were three, namely the Cognitive Style Test by using the Group Embedded Figure Test [31] ; Ability Test Proving Self-developed theorem with high reliability (0. 897); Mathematical Representation Capability Test is also self-developed with high reliability also (0.853). Data were collected by students' ability test after real-time learning process was carried out, both experiment and control class. The data of this study were analyzed by analysis of covariance (ANCOVA).

\section{RESULTS AND DISCUSSION}

Based on the analysis of research data, obtained a description of the ability profile to prove the theorem and mathematical representation of Mathematics Education students in Bengkulu. Students must have the ability to prove if reaching $85 \%$ completeness, as well as the ability of mathematical representation. 


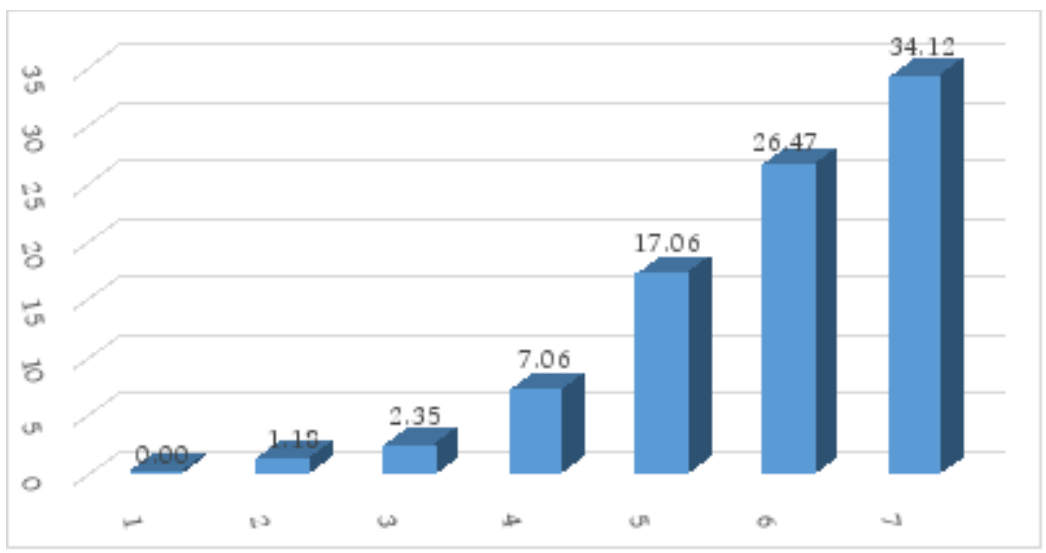

Fig. 1. Percentage Ability to Prove Students Based on Cognitive Structure Information:

1) Pre-Intra Level with a concrete object (Level 0)

2) Intra level with concrete objects (Level 1)

3) Semi-concrete level with Semi-concrete Model (Level 2)

4) Interlevel with the theoretical model (Level 3)

5) Semi-trans Level with Language in Domain instance (Level 4)

6) Trans Level with Math Language (Level 5)

7) Extended Level- Trans with Inference Model (Level 6)

Fig. 1. showed that the of significant in the ability to prove the theorem. The increasing happened after students follow real analysis by applying the extended triad model. There are $85.88 \%$ of students complete the theorems in the real analysis lecture. The student's completion percentage was divided into no students are at the Pre-Intra Level with concrete objects; $0.59 \%$ of students residing in the Intra Level with concrete objects; $176 \%$ of students who are at semi-inter level with Semi-concrete Model, $8.82 \%$ of students are at
Inter Level with theoretical model, $18.82 \%$ of students are at semi-trans level with Language in Domain example, 24.12\% Level Trans with Mathematics Language, and $34.12 \%$ of students are at Extended Level- Trans with Inference Model. It is appropriate for the research of Widada and Herawaty [1].

Furthermore, the percentage of student completeness in showing the ability of mathematical representation can be seen in Fig. 2.

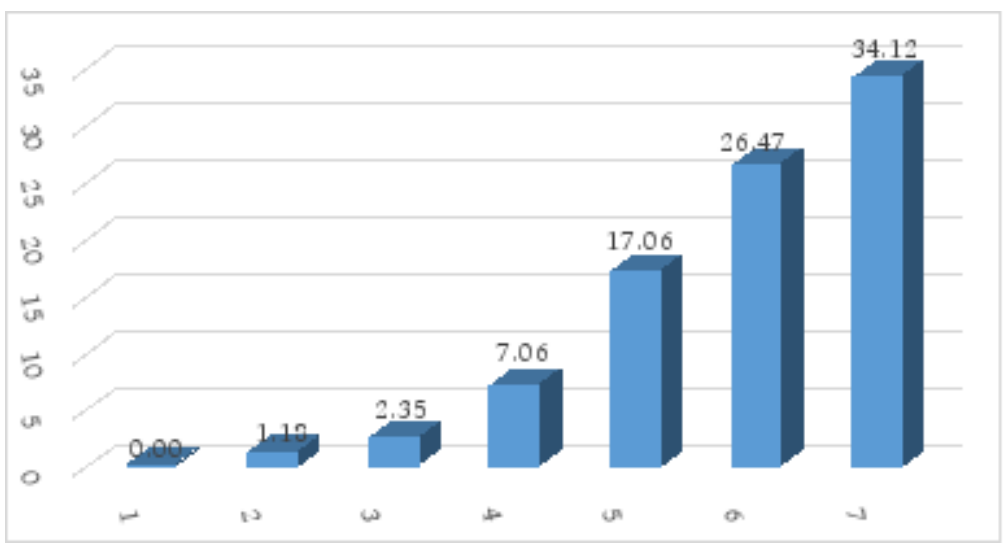

Fig. 2. Percentage of Student Mathematical Representation Ability Based on Cognitive Structure (Information 1-7 according to Fig. 1.)

Based on Fig. 2, 88.82\% of students have complete mathematical representation capability. This level of completeness was achieved after the students follow the extended triad learning. The students who were thoroughly divided into the following levels of cognitive structure. Students who were at Level 0 do 
not have a complete mathematical representation. In succession, the number of completed students at Level 1, Level 2, Level 3, Level 4, Level 5 and Level 6 are $1.18 \%, 2.35 \%, 7.06 \%, 20.00 \%, 26.47 \%$, and $35.29 \%$. The results of this study confirm the results of previous research conducted by Widada and Herawaty [1].
The description above of the data showed that the application of the extended triad learning model could improve the ability to prove the theorems and mathematical representations in real-time lecture analysis. It is supported by the following descriptive statistics.

Table 1 Descriptive Statistics Ability to Prove

\begin{tabular}{lrrr}
\hline Learning model & Mean & Std. Deviation & N \\
\hline Extended Triad Model & 78.219 & 5.464 & 64 \\
\hline Conventional Model & 27629 & 14910 & 62 \\
\hline Total & 53325 & 27718 & 126 \\
\hline
\end{tabular}

Table 1 showed that the students of the extended triad model have average ability to prove theorem greater than the conventional model students, the average score is 78.219 and 27.629 respectively.
Furthermore, the following table presents the average ability of students' mathematical representation of real analysis.

Table 2 Descriptive Statistics of Mathematical Representation Ability

\begin{tabular}{lrrr}
\hline Learning model & Mean & Std. Deviation & N \\
\hline Extended Triad Model & 79094 & 5.517 & 64 \\
\hline Conventional Model & 37.290 & 15473 & 62 \\
\hline Total & 58524 & 23.926 & 126 \\
\hline
\end{tabular}

Based on Table 2, the mathematical representation ability of the extended triad model was 79.094, and the conventional model student is 37.290. This result indicates that the students of the extended triad model have superior mathematical representation capabilities. To give a belief in the superiority of the extended triad learning model, the following is an inferential statistical test through ANCOVA. Levene's test in Table 3 tested the similarity of the error score of the ability to prove the theorem and the ability of mathematical representation.

Table 3 Levene's Test of Equality of Error Variances

\begin{tabular}{ccccc}
\hline $\begin{array}{c}\text { Dependent } \\
\text { Variable }\end{array}$ & $\mathrm{F}$ & $\mathrm{df} 1$ & $\mathrm{df} 2$ & Sig. \\
\hline Ability to Prove & .098 & 1 & 124 & .367 \\
\hline $\begin{array}{c}\text { Representational } \\
\text { Ability }\end{array}$ & 1.870 & 1 & 124 & .152 \\
\hline
\end{tabular}

Based on Table 3 showed that the variant of the ability scoring error proves for two sets of learning models (extended triads and conventional) is the same, with $F=0.098$ and sig. $=0.367>0.05$. The same thing happens for the variant of the error score of the ability of mathematical representation. There is no difference in the variant error score of mathematical representation ability for extended triad model and conventional model group. 
Table 4 Tests of Between-Subjects Effects

Dependent Variable: Ability to Prove

\begin{tabular}{cccccc}
\hline Source & $\begin{array}{l}\text { Type III Sum of } \\
\text { Squares }\end{array}$ & df & Mean Square & F & Sig. \\
\hline Corrected Model & $83046.492^{\text {a }}$ & 2 & 41523.246 & 393.080 & .000 \\
\hline Intercept & 76847.970 & 1 & 76847.970 & 727482 & .000 \\
\hline GK & 148.239 & 1 & 148.239 & 1.403 & .265 \\
\hline MP & 55403.537 & 1 & 55403.537 & 524.478 & .000 \\
\hline Error & 12993.167 & 123 & 105.636 & & \\
\hline Total & 454333.000 & 126 & & & \\
\hline Corrected Total & 96039659 & 125 & & & \\
\hline
\end{tabular}

a. R Squared =. 865 (Adjusted R Squared =. 863)

The influence test between the subjects in Table 4 showed that the covariate analysis model (ANCOVA) constructed is feasible. In the corrected model line produced $\mathrm{F}=393.080$ which is very significant with sig. $=0.000<0.05$. So the statistical test is continued by testing the role of covariate "cognitive style $=\mathrm{GK}$ " in determining the effect of two learning models on the ability to prove the theorem of real analysis. The GK row in Table 4 shows the significance number $0.265>0.05$ with $F=1.403$. This figure suggests that the role of cognitive-style covariates in determining the average difference of ability to prove theorems is insignificant. In other words, cognitive style variables do not significantly influence the average difference in the ability to prove the theorems of the two groups of extended triad model students and conventional model students. Prastiti's research [32] found that the ability of mathematical understanding was influenced by the learning approach. Therefore, consider the line MP (= Learning Model) in Table 4 showed a significant number of $0.00<0.05$ with $\mathrm{F}=524.478$. Thus, the influence of the extended triad learning model on the ability to prove the student theorem of real analysis is better than the conventional learning model when controlled by cognitive style covariates.

Table 5 Tests of Between-Subjects Effects

Dependent Variable: Mathematical Representation

\begin{tabular}{lrrrrr}
\hline Source & \multicolumn{2}{l}{$\begin{array}{l}\text { Type III Sum of } \\
\text { Squares }\end{array}$} & df & Mean Square & F \\
\hline Corrected Model & $56162.151^{\text {a }}$ & 2 & 28081.075 & 224.382 & Sig. \\
\hline Intercept & 54179.196 & 1 & 54179.196 & 432.919 & .000 \\
\hline GK & 1128.934 & 1 & 1128.934 & 9.021 & .163 \\
\hline MP & 30104.405 & 1 & 30104.405 & 240.549 & .000 \\
\hline Error & 15393.278 & 123 & 125149 & & \\
\hline Total & 503110.000 & 126 & & & \\
\hline Corrected Total & 71555.429 & 125 & & & \\
\hline
\end{tabular}

a. R Squared =. 785 (Adjusted R Squared =. 781)

Table 5 test of influence between subjects showed that the corrected model line is generated very significant number $0.00<0.05$ with $\mathrm{F}=224.382$. This figure indicates that the model of the ANCOVA made is correct. The statistical test of the role of the GK covariate in determining the difference of the effect of the two learning models on mathematical representation ability can be seen in the GK line. The table is showing the significance of $0.163>0.05$ with $\mathrm{F}=9.021$, which means that the role of cognitive style covariates is not significant in determining the average difference in the mathematical representation 
capabilities of the two groups of extended triad model students and conventional model students. Notice the MP row in Table 5, ANCOVA shows $\mathrm{F}=240.549$ with significant number $0.00<0.05$. Thus, the influence of the extended triad learning model on students' mathematical representation of real analysis more better than the conventional learning model when controlled by cognitive style covariates. The same thing found Sudarman et al., on the influence of learning strategies and cognitive styles on mathematical skills (such as problem-solving skills), as well as Prastiti on the influence of learning approaches and prior ability to the comprehension of mathematics $[29,32]$. The ability of understanding of mathematics in this research there are two that are reviewed is the ability to prove the theorem and the ability of mathematical representation.

\section{CONCLUSIONS}

The findings of this study indicate that the application of extended triad learning model can improve the ability to prove the theorems and mathematical representation in the lecture of real analysis convincingly. The result of covariance analysis showed that the effect of extended triad learning model on students' mathematical representation ability of real analysis more better than the conventional learning model when controlled by cognitive style covariate. The last conclusion, the effect of the extended triad learning model on students' ability of proofing theorem more better than the conventional learning model when controlled by cognitive style covariates. Based on the conclusions, the extended triad learning model is well worth replacing the conventional learning model. Finally, we would like to thank all the leaders of Bengkulu University, and the Director General of Research and Development, Ministry of Research, Technology and Higher Education of the Republic of Indonesia as a funder of this research.

\section{REFERENCES}

[1] W. Widada, and D. Herawaty, Genetic Decomposition of Mathematics Education Student Reviewed By Model Structure of Knowledge Representation (SRP) and Abstraction Ability (KA) about Real Analysis Concepts. The article is published in Proceedings of The 2016 Jambi International Seminar on Education, 3-5 April 2016, pp. 656665

[2] W. Widada, Development of Theory and Learning Model of Mathematics Based on Triad Level for Real Analysis Students (Study at FKIP University of Bengkulu). Competency Grant Research Report: Ditjen Dikti, 2009.

[3] W. Widada, Advanced Development Theory and Learning Model of Extended Graph Theory Triad Level for FKIP University Students of Bengkulu University. (Report of Competence Grant Research Result, Ditjen Dikti, 2010.

[4] W. Widada, Ability of Mathematics Student Abstraction in Understanding Concepts of Real Analysis is reviewed based on Cognitive Structure. The article is published in Proceedings of the SEMIRATA MIPA BKS West in Unsri (22-24 May 2016)

[5] Ed. Dubinsky, \& P. Lewin, Reflective abstraction and Mathematical Induction: The Decomposition of Induction and Compactness. The Journal of Mathematical Behavior. Vol. 5, 55-92. 1986. Online: http:www.ScienceDirect/science /journal/

[6] Ed. Dubinsky, Teaching Mathematical Induction.The Journal of Mathematical Behavior. 6 (1), 1987. http://www. ScienceDirect/science /journal/

[7] Ed. Dubinsky, (1989). On Teaching Mathematical Induction II. The Journal of Mathematical Behavior. Vol. 8. 1989. http: www. ScienceDirect/science /journal/

[8] Ed. Dubinsky, Using a Theory of Learning in College Mathematics Course. Newsletter. 1 (2), 2000. https://www.heacademy.ac.uk/system/files/msor.1.2f.pdf

[9] Ed. Dubinsky, ISELT: A Programming Language for Learning Mathematics. Communications on Pure and Applied Mathematics. 48 (9), 1985, pp. 1027-1051.

[10] Ed. Dubinsky, \& McDonald, A. Michael, APOS: A Constructivist Theory of Learning in Mathematics Education Research Undergraduate. 2000. http://www.telri.ac.uk/CM/Paper.pdf

[11] B. Baker, L. Cooley, \& M. Trigueros, A Calculus Graphing Schema. Journal for Research in Mathematical Education. 31 (5), 2000, pp. 557-578.

[12] W. Widada, Student Genetic Decomposition in Studying Graph Theory. Scientific Journal of Multi-Science Inspiration. (Monograph II Year 2006)

[13] W. Widada, The Existence of Students in Trans Extended Cognitive Development on Learning of Graph Theory. Journal of Math Educator Nusantara. 1 (1) pp. 1-20, 2015.

[14] W. Widada, Profile of Cognitive Structure of the Students in Understanding the Concept of Real Analysis. Infinity, 5 (2) pp $83-98,2016$

[15] J. Piaget, \& R. Garcia, Psychologies and the History of Science, 1989. http://www.piaget.org/

[16] W. Finzer, \& D. Bennett, Technology tips: From drawing to construction with The Geometer's Sketchpad. Mathematics Teacher, 88 (5) pp. 428-431, 1995.

[17] Stout, T., J. Dwyer, R. Byerly, J. Wilhelm, Assessing the Learning of Proofs in High School. International Journal for Mathematics Teaching and Learning ISSN 1473 - 0111, 2011. Online: http://www.cimt.org.uk/journal/dwyer3.pdf

[18] Knuth, Eric J. Proof as a Tool for Learning Mathematics. Mathematics Teacher. 95 (7) pp. 486-490, 2002.

[19] Baddely, Your Memory A User's Guide. London: Prion, 1998.

[20] G. E. Davis, \& D. O. Tall, What is a scheme? In D. O. Tall, \& M. O. J. Thomas (Eds.) Intelligence, learning, and understanding in mathematics. A tribute to Richard Skemp (pp. 131-150). Flaxton, Queensland, Australia: Post Pressed, 2002.

[21] R. R. Hunt, \& Ellis, C. Henry, Fundamental of Cognitive Psychology. Sixth Edition. Boston: McGraw-Hill College, 1999.

[22] R. L.Solso, Cognitive Psychology. Boston: Allyn and Bacon, 1995.

[23] M. de Villiers, Explanation and Proof in Mathematics Philosophical and Educational Perspectives (Springer Science + Business Media, London, 2010)

[24] W. Widada, Abstraction Ability Learners in Understanding Objects Geometry. Articles published in Proceedings of International Seminar of 17 January 2015. pp. 505-512.

[25] W. Widada, Syntax of Mathematics Learning Model Based on Cognitive Development of Learners. Jurnal Pendidikan Matematika Raflesia. 1 (2), pp. 163-172, 2016.

[26] J. E. Pretz, K. S. Totz, S. S. Kaufman, The effects of mood, cognitive style, and cognitive ability in implicit learning. 
Learning and Individual Differences, 2010. doi:10.1016/j.lindif.2009.12.003.

[27] H. A. Witkin, C. A. Moore, D. R. Goodenough, \& P. W. Cox, Field-Dependent and Field-Independent Cognitive Styles and Their Educational Implications. Review of Educational Research. Winter. 47 (1), pp. 1-64, 1977.

[28] C. PeklaJ, Psiholoska obzorja / Horizons of Psychology. 12 (4), pp. 9-22, 2003.

[29] Sudarman, S. Punaji, Dedi K. Wasis D. D. The Effect of Learning Strategy and Cognitive Style toward Mathematical Problem Solving Learning Outcomes. IOSR Journal of Research \& Methods in Education (IOSR-JRME) e-ISSN: 2320-7388. (6) 3 Ver. IV (May. -Jun. 2016), pp. 137-143

[30] T. G. Ratumanan, The Influence of Learning Model and Cognitive Style on Junior High School Student Learning Outcomes in Ambon City. Journal of Basic Education. 5 (1), pp. 1-10, 2003.

[31] H.A. Witkin, P.K. Oltman, E. Raskin, \& S.A. Karp, A Manual for the Embedded Figures Tests, Children's Embedded Figures Test, Embedded Figures Test Group. California: Consulting Psychology Press Inc., 1971.

[32] T. D. Prastiti, Influence of Instruction Approach RME and Early Knowledge to Communication Skill and Understanding of Mathematics of VII Grade VII Students. Didaktika. 2 (1), pp. 199-215, 2007 